\title{
Valor nutricional e energia metabolizável de subprodutos do trigo utilizados para alimentação de suínos em crescimento
}

\author{
William Rui Wesendonck(1), Alexandre de Mello Kessler(1), Andréa Machado Leal Ribeiro(1), \\ Marcelo Luiz Somensi(1), Luciane Bockor ${ }^{(1)}$, Julio Cezar Dadalt(2), \\ Alessandra Nardina Trícia Rigo Monteiro(1) e Fábio Ritter Marx ${ }^{(1)}$
}

\begin{abstract}
(1)Universidade Federal do Rio Grande do Sul, Departamento de Zootecnia, Avenida Bento Gonçalves, no 7.712, CEP 91540-000 Porto Alegre, RS. E-mail: williamzoo@yahoo.com.br, akessler@ufrgs.br, aribeiro@ufrgs.br, mlsomensi@hotmail.com, lubockor@hotmail.com, a_monteiro@zootecnista.com.br, fabioritter@msn.com (2)Universidade de São Paulo, Faculdade de Medicina Veterinária e Zootecnia, Departamento de Nutrição e Produção Animal, Avenida Duque de Caxias Norte, o 225, CEP 13635-900 Pirassununga, SP. E-mail: julio@zootecnista.com.br
\end{abstract}

\begin{abstract}
Resumo - O objetivo deste trabalho foi avaliar o valor nutricional e energético de subprodutos do trigo, em dietas para suínos em crescimento, e obter equações de predição da energia metabolizável. Foram utilizados 36 suínos machos, castrados, alojados em gaiolas metabólicas individuais. Realizou-se a coleta total de fezes e urina em dois períodos de dez dias: cinco para adaptação e cinco para coleta. Utilizou-se o delineamento de blocos ao acaso, tendo-se considerado o período de coleta como bloco, com seis tratamentos e seis repetições. A dieta referência foi substituída em $30 \%$ por um dos subprodutos testados: farinheta, farelo fino, farelo de trigo, farelo grosso e farelo grosso moído; este último usado para avaliar a influência da granulometria na digestibilidade. A fibra bruta foi a variável que proporcionou a melhor estimativa da energia metabolizável. O farelo fino foi superior em energia digestível e metabolizável, em comparação ao farelo grosso moído. O farelo grosso moído apresentou os menores coeficientes de digestibilidade, e a diminuição de seu diâmetro geométrico médio não aumentou a digestibilidade dos nutrientes e da energia. Entre os subprodutos avaliados, a farinheta apresenta maior energia digestível, energia metabolizável e proteína digestível, o que mostra elevado potencial para utilização em dietas para suínos em crescimento.
\end{abstract}

Termos para indexação: alimentos alternativos, digestibilidade, fibra, granulometria, metabolizabilidade.

\section{Nutritional value and metabolizable energy of wheat by-products used for feeding growing pigs}

\begin{abstract}
The objective of this work was to evaluate nutritional and energy values of wheat by-products in diets for growing pigs, and to obtain prediction equations for metabolizable energy. Thirty-six male pigs were housed in individual metabolic cages. Total collection of feces and urine was carried out in two periods of ten days: five days for adaptation and five days for collection. A randomized complete block design was used, considering the sampling period as a block, with six treatments and six replicates. The reference diet was replaced by $30 \%$ of one of the tested by-products: wheat middlings, fine wheat bran, common wheat bran, coarse wheat bran, and ground coarse wheat bran; the latter was used to evaluate the influence of particle size on digestibility. Crude fiber was the variable that provided the best estimate of metabolizable energy. Fine wheat bran was superior in terms of digestible and metabolizable energy, when compared to coarse wheat bran. Ground coarse wheat bran showed lower digestibility coefficients, and the reduction in its average geometric diameter did not increase nutrient availability. Among the evaluated by-products, wheat middlings have higher digestible energy, metabolizable energy, and digestible protein, showing high potential use in diets for growing pigs.
\end{abstract}

Index terms: alternative foods, digestibility, fiber, particle size, metabolizability.

\section{Introdução}

No Brasil, aproximadamente 10 milhões de toneladas de trigo são beneficiadas por ano. Deste total, cerca de $75 \%$ é destinado à produção de farinha de trigo utilizada na alimentação humana, e os $25 \%$ restantes são considerados resíduos, comumente vendidos como farelo de trigo (Associação Brasileira da Indústria do Trigo, 2012).

Os subprodutos do processamento do grão de trigo (farinheta, farelo fino e farelo grosso) apresentam diferentes granulometrias e composições nutricionais. No entanto, não há conhecimento de trabalhos, no Brasil, com informações sobre a composição química 
e a disponibilidade nutricional dessas frações para suínos. As tabelas nacionais de composição de alimentos fornecem valores apenas para farelo de trigo. Rostagno et al. (2011), por exemplo, apresentam valores de 3.914, 2.504 e $2.390 \mathrm{kcal} \mathrm{kg}^{-1}$ em energia bruta, digestível e metabolizável do farelo de trigo para suínos, respectivamente. As tabelas internacionais, contudo, mostram valores de subprodutos específicos, como as elaboradas pelo National Research Council (2012) para suínos, que apresenta valores para farelo de trigo ("wheat bran") e para subprodutos equivalentes à farinheta ("wheat middlings") e ao farelo fino ("wheat shorts").

A energia metabolizável é a melhor forma de expressar a energia disponível nos alimentos, e pode ser determinada de forma direta e indireta. Na primeira maneira, busca-se o conhecimento do valor nutricional e energético do alimento por meio de ensaios biológicos. A partir destas informações, é possível obter modelos matemáticos que predigam o conteúdo de energia metabolizável de forma indireta, por meio das composições química e física dos alimentos. Além de ter fácil aplicabilidade na indústria, o uso de equações de predição da energia permite maximizar a utilização dos dados de composição obtidos mediante análises laboratoriais de rotina (Rostagno et al., 2007).

A utilização dos diferentes subprodutos do beneficiamento do trigo na alimentação animal representa uma alternativa de maior precisão na formulação das dietas, o que possibilitaria redução no custo final da ração. Contudo, ainda há carência de dados brasileiros sobre esses ingredientes.

O objetivo deste trabalho foi avaliar o valor nutricional e energético de subprodutos do trigo, em dietas para suínos em crescimento, e obter equações de predição da energia metabolizável.

\section{Material e Métodos}

O trabalho foi realizado no Laboratório de Ensino Zootécnico da Universidade Federal do Rio Grande do Sul (UFRGS), nos períodos de 20 a 30 de junho e 1 a 10 de julho de 2011. Foram utilizados 36 suínos, machos castrados, de linhagem comercial (machos Agroceres e fêmeas DB-DanBred), alojados em gaiolas metabólicas individuais. $\mathrm{O}$ experimento foi dividido em dois períodos de dez dias, com cinco dias de adaptação e cinco dias de coleta total de fezes e urina. Os suínos iniciaram o experimento com $49 \pm 1,3$ e $59 \pm 1,9 \mathrm{~kg}$, no primeiro e no segundo período, respectivamente.

Utilizou-se o delineamento experimental de blocos ao acaso, com seis tratamentos e seis repetições cada um, e os períodos de adaptação e de coleta total de fezes foram considerados como blocos. Os tratamentos consistiram de dieta referência (Tabela 1), elaborada de acordo com as recomendações nutricionais propostas por Rostagno et al. (2011), e de cinco dietas teste, compostas de $70 \%$ da dieta referência e $30 \%$ de um dos subprodutos: farinheta, farelo fino, farelo grosso, farelo de trigo e farelo grosso moído. Os diferentes farelos foram incluídos na dieta referência pelo método de substituição, e seus respectivos níveis nutricionais e granulometrias estão apresentados na Tabela 2 . O farelo de trigo, a farinheta, o farelo fino e o farelo grosso foram obtidos em moinhos de trigo locais; já o farelo grosso moído, foi preparado na fábrica de ração experimental do Laboratório de Ensino Zootécnico da UFRGS, tendo passado por moagem em moinho de martelos, com peneira de $1 \mathrm{~mm}$.

A alimentação dos animais foi ajustada com base no peso metabólico inicial $\left(\mathrm{PV}^{0,60}\right)$ e a quantidade diária ofertada foi ajustada à estimativa do ganho de peso médio diário, tendo-se considerado um consumo de energia de 2,6 vezes a mantença (Noblet et al., 1993). Assim, o consumo diário foi calculado como 2,6 $\times$ $250 \mathrm{kcalEM} \times \mathrm{PV}^{0,60} / \mathrm{EM}$ da dieta. Os animais receberam água à vontade, e as dietas foram distribuídas em duas refeições diárias (às $8 \mathrm{~h}$ e às $17 \mathrm{~h}$ ).

Foi utilizado o método de colheita total de fezes e urina, e o início e o final da coleta foi determinado pelo aparecimento de fezes marcadas pela adição de $0,25 \%$ do marcador $\mathrm{Fe}_{2} \mathrm{O}_{3}$ às dietas. Duas vezes ao dia (às $10 \mathrm{~h}$ e às $18 \mathrm{~h}$ ), as fezes foram colhidas e pesadas, e uma alíquota de $20 \%$ do total produzido foi acondicionada em sacos de plástico e conservada sob refrigeração a $-10^{\circ} \mathrm{C}$. Desta alíquota, em torno de $300 \mathrm{~g}$ de amostra de fezes foram secos em estufa de ventilação de ar forçada, a $60^{\circ} \mathrm{C}$, por 72 horas, e moídos para análises posteriores. A urina excretada foi drenada para baldes de plástico com $5 \mathrm{~mL}$ de $\mathrm{H}_{2} \mathrm{SO}_{4}$, para evitar proliferação bacteriana e possíveis perdas por volatilização, tendo sido realizada pesagem diária do total excretado e retirada uma alíquota de $10 \%$, conservada sob refrigeração a $-10^{\circ} \mathrm{C}$. Uma amostra de urina de cada animal foi seca em estufa de ventilação de ar forçada, a $60^{\circ} \mathrm{C}$, por 72 horas, e analisada quanto 
à energia bruta. A determinação da proteína bruta da urina foi realizada na matéria natural.

As amostras de farinheta, farelo fino, farelo grosso, farelo de trigo, farelo grosso moído, dieta referência e fezes foram moídas em moinho de facas e analisadas segundo a AOAC (Horwitz, 2005) quanto a: matéria seca (MS), matéria orgânica (MO), proteína bruta $(\mathrm{PB})$, cinzas $(\mathrm{Cz})$, fibra bruta $(\mathrm{FB})$, fósforo $(\mathrm{P}) \mathrm{e}$ cálcio $(\mathrm{Ca})$. A energia bruta $(\mathrm{EB})$ foi determinada em calorímetro de bomba isoperibólico, modelo C2000 (IKA-Werke GmbH \& Co., Staufen, Alemanha). A fibra em detergente ácido (FDA) e a fibra em detergente neutro (FDN), nas dietas e nos subprodutos, foram determinadas de acordo com Goering \& Van Soest (1970). O diâmetro geométrico médio (DGM) foi determinado segundo Zanotto \& Bellaver (1996). As respostas de digestibilidade e metabolizabilidade dos diferentes subprodutos do farelo de trigo foram obtidas pelo método de substituição. Os valores da

Tabela 1. Composição da dieta referência.

\begin{tabular}{lc}
\hline Ingredientes & Dieta referência \\
\hline & Participação (\%) \\
Milho & 72,83 \\
Farelo de soja 44 & 21,87 \\
Óleo de soja & 2,00 \\
Calcário & 1,44 \\
Fosfato bicálcico & 1,13 \\
Sal & 0,47 \\
L-Lisina HCl & 0,06 \\
Antioxidante & 0,02 \\
Cl-Colina (60\%) & 0,06 \\
Premix vitamínico ${ }^{(1)}$ & 0,03 \\
Premix mineral ${ }^{(2)}$ & 0,06 \\
\hline & Análise proximal \\
Matéria seca (\%) & 87,86 \\
Energia bruta $\left(\mathrm{kcal} \mathrm{kg}^{-1}\right)^{(3)}$ & 4515 \\
Proteína bruta $(\%)$ & 16,74 \\
Fibra bruta (\%) & 2,48 \\
FDN (\%) & 9,86 \\
FDA (\%) & 2,68 \\
Gordura (\%) & 5,04 \\
Cálcio (\%) & 0,94 \\
Fósforo total $(\%)$ & 0,58 \\
DGM ( $\mu$ m) & 541 \\
\hline
\end{tabular}

(1)Adição por kg de dieta: vitamina A, $11.200 \mathrm{UI}$; vitamina D3, $2.100 \mathrm{UI}$; vitamina E, 25,2 mg; vitamina $\mathrm{K}, 2,8 \mathrm{mg}$; vitamina $\mathrm{B} 1,2,24 \mathrm{mg}$; vitamina B2, 7,14 mg; vitamina B6, 2,17 mg; vitamina B12, 26,6 $\mu \mathrm{g}$; ácido pantotênico, 18,2 mg; niacina, 36,4 mg; ácido fólico, 0,63 mg; biotina, $126 \mathrm{mcg}$. ${ }^{(2)}$ Adição por $\mathrm{kg}$ de dieta: selênio, $0,39 \mathrm{mg}$; iodo, 0,46 mg; ferro, $52 \mathrm{mg}$; cobre, 10,4 mg; zinco, $104 \mathrm{mg}$; Mn, $39 \mathrm{mg}$. ${ }^{(3)}$ Valores expressos com base na matéria seca. FDN, fibra em detergente neutro; FDA, fibra em detergente ácido; DGM, diâmetro geométrico médio. energia digestível (ED) e metabolizável (EM) aparente, PB digestível, Ca digestível, $P$ digestível e FB digestível dos farelos foram determinados com as fórmulas desenvolvidas por Campbell et al. (1983), em que se utilizou, como exemplo, o cálculo da ED aparente, $\mathrm{ED}_{\text {ingr }}=\mathrm{EB}_{\text {ingr }}-\left\{\left[\mathrm{EE}_{\text {ing }}-(1-\mathrm{X}) \times \mathrm{EE}_{\mathrm{REF}}\right] / \mathrm{X}\right\}$, em que: $E D_{\text {ingr }}$ é a energia digestível do ingrediente; $E_{\text {ingr }}$ é a energia bruta do ingrediente; $E_{\text {ingr }}$ é a energia excretada do tratamento com o ingrediente teste; $E_{\mathrm{REF}}$ é a energia excretada do tratamento com a dieta referência; e X é o nível de substituição do ingrediente teste à dieta referência.

Os coeficientes de digestibilidade aparente da matéria seca (CDMS), da energia bruta (CDEB), da proteína bruta (CDPB), da matéria orgânica (CDMO), da fibra bruta (CDFB), bem como o balanço de $\mathrm{Ca}$ e $\mathrm{P}$ das dietas completas, foram determinados com cálculos padrões, segundo Sakomura \& Rostagno (2007). Os coeficientes de digestibilidade aparente foram calculados pela razão entre o nutriente digestível estimado e o conteúdo total no ingrediente, tendo-se usado, como exemplo, o coeficiente de digestibilidade aparente da energia bruta, $\mathrm{CDEB}_{\text {ingr }}=\mathrm{ED}_{\text {ingr }} / \mathrm{EB}_{\text {ingr }} \times 100$, em que: $\mathrm{CDEB}_{\text {ingr }}$ é o coeficiente de digestibilidade aparente da $\mathrm{EB}_{\text {ingr }} ; \mathrm{ED}_{\text {ingr }}$ é a energia digestível do ingrediente; e $\mathrm{EB}_{\text {ingr }}$ é a energia bruta do ingrediente.

A digestibilidade verdadeira do fósforo foi estimada pela metodologia de Fang et al. (2007), a qual possibilita a correção para perda endógena, com uso da fórmula,

$$
\mathrm{DV}(\%)=\left[\left(\mathrm{PTD}_{2}-\mathrm{PF}_{2}\right)-\left(\mathrm{PTD}_{1}-\mathrm{PF}_{1}\right)\right] /\left(\mathrm{PTD}_{1}-\mathrm{PF}_{1}\right) \text {, }
$$

Tabela 2. Níveis nutricionais e diâmetro geométrico médio (DGM) dos subprodutos farinheta, farelo fino, farelo grosso, farelo de trigo e farelo grosso moído.

\begin{tabular}{lccccc}
\hline Composição & $\begin{array}{c}\text { Farinheta } \\
\text { Farelo } \\
\text { fino }\end{array}$ & $\begin{array}{c}\text { Farelo } \\
\text { grosso }\end{array}$ & $\begin{array}{c}\text { Farelo } \\
\text { de trigo }\end{array}$ & $\begin{array}{c}\text { Farelo } \\
\text { grosso } \\
\text { moído }\end{array}$ \\
\hline Matéria seca (\%) & 87,47 & 85,92 & 86,30 & 86,14 & 86,80 \\
Energia bruta (kcal kg $\left.)^{-1}\right)^{(1)}$ & 4.651 & 4.673 & 4.590 & 4.618 & 4.581 \\
Proteína bruta (\%) & 18,48 & 18,14 & 17,53 & 17,14 & 17,05 \\
Fibra bruta (\%) & 5,78 & 8,61 & 10,14 & 9,95 & 10,06 \\
FDN (\%) & 29,10 & 42,78 & 48,20 & 42,61 & 46,35 \\
FDA (\%) & 8,23 & 12,27 & 13,73 & 12,59 & 13,11 \\
Gordura (\%) & 4,97 & 5,27 & 2,94 & 2,84 & 3,44 \\
Cálcio (\%) & 0,06 & 0,06 & 0,06 & 0,06 & 0,07 \\
Fósforo total (\%) & 0,73 & 0,91 & 1,07 & 0,93 & 1,13 \\
DGM $(\mu \mathrm{m})$ & 257 & 541 & 1.111 & 569 & 464 \\
\hline
\end{tabular}

${ }^{(1)}$ Valores expressos com base na matéria seca. FDN, fibra em detergente neutro; FDA, fibra em detergente ácido. 
em que: DV é a digestibilidade verdadeira do fósforo; $\mathrm{PTD}_{\mathrm{i}}$ é o fósforo total da dieta; $\mathrm{PF}_{\mathrm{i}}$ é o fósforo fecal; e o i refere-se a dieta 1 ou 2 (dieta 1, com ingrediente teste; dieta 2 , a referência).

Os dados foram submetidos à análise de variância, e as médias dos tratamentos foram comparadas pelo teste de Student-Newman-Keuls. Após a determinação da EM, utilizaram-se os dados de composição química e física dos ingredientes para obter equações de regressão linear múltipla, calculadas pelo método stepwise de eliminação indireta ("backward"). Todas as análises foram realizadas por meio do procedimento "general linear model" (GLM) do programa estatístico Statgraphics Plus 4.1.

\section{Resultados e Discussão}

Os valores de MS encontrados para os diferentes subprodutos ficaram entre 85,9 e $87,4 \%$, considerados relativamente baixos se comparados aos de outros subprodutos utilizados na alimentação de suínos, provavelmente em razão da adição de água no trigo durante o processo de moagem. Contudo, esses valores são similares aos reportados por Rostagno et al. (2011), que obtiveram valores de $88,38 \%$ para farelo de trigo comum, e por Silva (2006), que obteve $85,87 \%$, para farelo fino, e 83,65\% para farelo grosso (Tabela 2).

Todos os subprodutos proporcionaram valores similares de EB; entretanto, a farinheta, quando comparada ao farelo fino, ao farelo grosso, ao farelo de trigo e ao farelo grosso moído, apresentou menores valores de FB, FDN, FDA e menor DGM (Tabela 2). Estes resultados estão relacionados ao fato de a farinheta ser obtida nas peneiras de menor DGM de separação de farinha e subprodutos, o que gera um subproduto com partículas de pericarpo mais finas e menos fragmentadas. Já o farelo grosso, apresentou os maiores valores de FB, FDN, FDA e DGM, resultado do processo de extração do grão de trigo, no qual esse farelo provém da camada mais externa que recobre o grão, que apresenta maior porção fibrosa. O teor de $\mathrm{Ca}$ dos subprodutos foi semelhante; na farinheta, observou-se baixa concentração de fósforo total, cerca de $30 \%$ a menos que nos demais subprodutos.

Conforme o grau e as etapas da moagem aplicada, decorrentes do modelo de fluxograma empregado no beneficiamento, o farelo de trigo pode variar em composição e tamanho das partículas, o que é influenciado, principalmente, pela quantidade de farinha residual (Blas Beorlegui, 2003). Dados de Dobraszczyk et al. (2002) e Carre (2004) mostram que o DGM obtido não depende somente da abertura de peneiras, da distância entre martelos e da potência do moinho utilizado, mas, também, da dureza dos grãos, da umidade e do teor de óleo, entre outros fatores.

A digestibilidade aparente de MS, PB, EB, MO, FB e os valores de ED, EM, balanço aparente de Ca e $\mathrm{P}$ das dietas teste apresentaram diminuição significativa em relação à dieta referência (Tabela 3 ). Estes resultados eram esperados uma vez que as dietas teste sofreram um desbalanço nutricional, como resultado do método de substituição. Segundo Kunrath et al. (2010), o nível crescente de substituição do ingrediente teste pode influenciar, de forma negativa, a digestibilidade dos nutrientes da dieta.

Os coeficientes de digestibilidade aparente dos nutrientes avaliados foram menores nas dietas que continham os subprodutos do trigo. Isso pode estar relacionado à composição química destes ingredientes, ricos em polissacarídeos não amiláceos, que aumentam a viscosidade da digesta e aceleram sua passagem pelo trato gastrintestinal, o que reduz a fermentação dos carboidratos estruturais. Outros autores demonstraram que as digestibilidades de MS, EB (Nortey et al., 2008), PB, FDN e FDA (Gomes et al., 2007) são afetadas, negativamente, pelo aumento do conteúdo de fibra bruta na dieta de suínos em crescimento.

Em trabalho com alimentos alternativos - quirera de arroz, milheto, sorgo baixo tanino e farelo de trigo -, Apolônio et al. (2003) obtiveram valor de CDPB de $62,75 \%$ para farelo de trigo, semelhante ao do presente trabalho (Tabela 4). A dieta com farelo de trigo foi a que apresentou maior teor de FB (4,51\%). Dietas que continham em torno de $2 \%$ de FB apresentaram valores de CDPB acima de 85\%. Houve diferença significativa no balanço do $\mathrm{Ca}$ entre os animais que receberam dieta com farelo grosso e farelo grosso moído, e o balanço do $\mathrm{Ca}$ foi maior para a primeira. Esta diferença pode ser resultante da variação analítica das dietas experimentais. A dieta com farelo grosso apresentou $0,79 \%$ de $\mathrm{Ca}$, enquanto a dieta com farelo grosso moído apresentou 0,74\%. Esta discrepância analítica em dietas cujo valor de $\mathrm{Ca}$ deveria ser similar pode gerar variações nos coeficientes de digestibilidade e é a principal justificativa da modificação ao método de substituição, proposta por Campbell et al. (1983), no cálculo da disponibilidade aparente de nutrientes em ingredientes. 
O balanço de fósforo não apresentou diferenças significativas entre as dietas teste e a dieta referência, o que mostra que a inclusão de fósforo fítico oriundo dos subprodutos do trigo não alterou a digestibilidade do fósforo total da dieta (Tabela 3). Este resultado está relacionado ao fato de cereais como o trigo apresentarem alta atividade de fitase endógena (1.200 UI kg $\left.{ }^{-1}\right)$ (Eeckhout $\&$ De Paepe, 1991). Han et al. (1997) demonstraram que a inclusão de 100 e $200 \mathrm{~g} \mathrm{~kg}^{-1}$ de farelo de trigo, em dietas para suínos em crescimento e terminação, apresentaram atividade de fitase suficiente, ao ponto de dispensar a suplementação de fósforo inorgânico.
Verificou-se aumento significativo na digestibilidade verdadeira do fósforo para a dieta com farinheta, em relação ao farelo fino e ao farelo grosso. $\mathrm{O}$ balanço de fósforo e a digestibilidade verdadeira são duas formas de se avaliar a utilização biológica deste mineral pelos suínos. Os alimentos com menor conteúdo de fósforo total, como a farinheta, apresentam maiores diferenças entre o balanço de fósforo e a digestibilidade verdadeira deste mineral. Neste caso, o fósforo de origem endógena, que participa em maior proporção na quantidade de fósforo excretado nas fezes e que é descontado no cálculo da digestibilidade verdadeira,

Tabela 3. Consumo de ração, coeficientes de digestibilidade aparente da matéria seca (CDMS), proteína bruta (CDPB), energia bruta (CDEB), matéria orgânica (CDMO), fibra bruta (CDFB), energia digestível (ED) e energia metabolizável (EM), com base na matéria seca, e balanço aparente de cálcio (Bal.Ca), fósforo (Bal.P) e digestibilidade verdadeira do fósforo (DVP) das dietas experimentais ${ }^{(1)}$.

\begin{tabular}{|c|c|c|c|c|c|c|c|c|}
\hline \multirow[t]{2}{*}{ Variável } & \multicolumn{6}{|c|}{ Dieta $^{(2)}$} & \multirow[t]{2}{*}{$\mathrm{p}$} & \multirow[t]{2}{*}{ Erro-padrãc } \\
\hline & Ref. & Ref.+FA & Ref.+FF & Ref.+FG & Ref.+FT & Ref.+FGM & & \\
\hline Consumo (g por dia) & $1.981 \mathrm{a}$ & $2.109 b$ & $2.110 \mathrm{~b}$ & $2.095 b$ & $2.108 b$ & $2.129 \mathrm{~b}$ & $<0,0001$ & 196,7 \\
\hline CDMS (\%) & $87,76 \mathrm{a}$ & $83,71 \mathrm{~b}$ & $80,23 \mathrm{c}$ & $78,78 \mathrm{~cd}$ & $79,30 \mathrm{~cd}$ & $77,94 d$ & $<0,0001$ & 1,41 \\
\hline CDPB (\%) & $85,41 \mathrm{a}$ & $83,13 a b$ & $80,44 b$ & $80,45 b$ & $79,92 b$ & $80,00 \mathrm{~b}$ & 0,0003 & 2,09 \\
\hline CDEB (\%) & $87,70 \mathrm{a}$ & $83,70 \mathrm{~b}$ & $80,25 \mathrm{c}$ & $78,58 \mathrm{~cd}$ & $79,44 \mathrm{~cd}$ & $77,95 \mathrm{~d}$ & $<0,0001$ & 1,36 \\
\hline CDMO (\%) & $89,64 a$ & $85,30 \mathrm{~b}$ & $82,19 \mathrm{c}$ & $80,67 \mathrm{~cd}$ & $80,97 \mathrm{~cd}$ & $79,83 \mathrm{~d}$ & $<0,0001$ & 1,35 \\
\hline CDFB (\%) & $54,48 \mathrm{a}$ & $36,61 b$ & $32,56 \mathrm{bc}$ & $26,50 \mathrm{c}$ & $30,39 b c$ & $26,19 \mathrm{c}$ & $<0,0001$ & 6,10 \\
\hline $\mathrm{ED}\left(\mathrm{kcal} \mathrm{kg}^{-1}\right)$ & $3.960 \mathrm{a}$ & $3.815 \mathrm{~b}$ & $3.660 \mathrm{c}$ & $3.534 \mathrm{~d}$ & $3.594 \mathrm{~cd}$ & $3.525 \mathrm{~d}$ & $<0,0001$ & 66,43 \\
\hline $\mathrm{EM}\left(\mathrm{kcal} \mathrm{kg}^{-1}\right)$ & $3.849 \mathrm{a}$ & $3.698 b$ & $3.550 \mathrm{c}$ & $3.427 \mathrm{~d}$ & $3.491 \mathrm{~cd}$ & $3.415 \mathrm{~d}$ & $<0,0001$ & 65,26 \\
\hline Bal.Ca (\%) & $55,02 \mathrm{ab}$ & $52,55 \mathrm{ab}$ & $47,79 \mathrm{ab}$ & $62,34 \mathrm{a}$ & $52,79 \mathrm{ab}$ & $46,09 b$ & 0,0450 & 8,72 \\
\hline Bal.P (\%) & 47,46 & 50,70 & 44,60 & 44,92 & 48,55 & 42,16 & 0,3259 & 6,86 \\
\hline DVP (\%) & - & $70,4 a$ & $48,2 \mathrm{~b}$ & $40,0 \mathrm{~b}$ & $48,6 \mathrm{~b}$ & $44,5 b$ & 0,0153 & 13,46 \\
\hline
\end{tabular}

${ }^{(1)}$ Médias seguidas de letras iguais, nas linhas, não diferem pelo teste de Student-Newman-Keuls. ${ }^{(2)}$ Ref., dieta referência; FA, farinheta; FF, farelo fino; FG, farelo grosso; FT, farelo de trigo; FGM, farelo grosso moído.

Tabela 4. Coeficientes de digestibilidade de matéria seca (CDMS), energia bruta (CDEB), proteína bruta (CDPB), cálcio (CDCa), fósforo (CDP), fibra bruta (CDFB), energia digestível (ED), energia metabolizável (EM), e proteína, cálcio, fósforo e fibra digestíveis de farinheta, farelo fino, farelo grosso, farelo de trigo e farelo grosso moído para suínos em crescimento ${ }^{(1)}$.

\begin{tabular}{|c|c|c|c|c|c|c|c|}
\hline \multirow[t]{2}{*}{ Variável } & \multicolumn{5}{|c|}{ Ingrediente $^{(2)}$} & \multirow[t]{2}{*}{$\mathrm{p}$} & \multirow[t]{2}{*}{ Erro-padrão } \\
\hline & Farinheta & $\begin{array}{c}\text { Farelo } \\
\text { fino }\end{array}$ & $\begin{array}{l}\text { Farelo } \\
\text { grosso }\end{array}$ & $\begin{array}{c}\text { Farelo } \\
\text { de trigo }\end{array}$ & $\begin{array}{l}\text { Farelo grosso } \\
\text { moído }\end{array}$ & & \\
\hline CDMS (\%) & $74,11 \mathrm{a}$ & $61,62 b$ & $56,89 b$ & $58,58 b$ & $54,34 \mathrm{~b}$ & $<0,0001$ & 5,01 \\
\hline CDEB (\%) & $75,91 \mathrm{a}$ & $63,55 b$ & $58,20 \mathrm{bc}$ & $60,79 b c$ & $55,55 \mathrm{c}$ & $<0,0001$ & 4,88 \\
\hline CDPB (\%) & $77,03 \mathrm{a}$ & $68,43 \mathrm{ab}$ & $66,70 \mathrm{ab}$ & $64,97 b$ & $63,98 b$ & 0,0361 & 7,30 \\
\hline $\mathrm{CDCa}(\%)$ & 49,90 & $-150,90$ & $-79,85$ & $-24,24$ & $-110,98$ & 0,4471 & 195,85 \\
\hline CDP (\%) & 46,73 & 23,84 & 28,91 & 39,56 & 31,62 & 0,0519 & 13,38 \\
\hline CDFB (\%) & 20,45 & 18,03 & 16,73 & 19,16 & 14,75 & 0,9132 & 11,02 \\
\hline $\mathrm{ED}\left(\mathrm{kcal} \mathrm{kg}^{-1}\right)$ & $3.460 \mathrm{a}$ & $2.899 \mathrm{~b}$ & $2.618 b c$ & $2.751 b c$ & $2.512 \mathrm{c}$ & $<0,0001$ & 219,34 \\
\hline $\mathrm{EM}\left(\mathrm{kcal} \mathrm{kg}^{-1}\right)$ & $3.329 \mathrm{a}$ & $2.786 b$ & $2.519 b c$ & $2.661 b c$ & $2.399 \mathrm{c}$ & $<0,0001$ & 215,43 \\
\hline Proteína digestível (\%) & $14,23 \mathrm{a}$ & $12,41 b$ & $11,69 b$ & $11,14 b$ & $10,91 b$ & 0,0011 & 1,29 \\
\hline Cálcio digestível (\%) & 0,03 & $-0,09$ & $-0,05$ & $-0,01$ & $-0,09$ & 0,3797 & 0,12 \\
\hline Fósforo digestível (\%) & 0,34 & 0,22 & 0,31 & 0,37 & 0,36 & 0,2978 & 0,13 \\
\hline Fibra digestível (\%) & 1,18 & 1,55 & 1,70 & 1,91 & 1,48 & 0,7489 & 0,95 \\
\hline
\end{tabular}

${ }^{(1)}$ Médias seguidas de letras iguais, nas linhas, não diferem pelo teste Student-Newman-Keuls. ${ }^{(2)}$ Valores expressos com base na matéria seca. 
mas não no balanço, justifica as diferenças observadas (Bünzen et al., 2008), que foram acima de 13\% entre as duas metodologias.

A digestibilidade aparente de MS, EB e PB da farinheta foi significativamente maior que a dos demais alimentos avaliados (Tabela 4). Este resultado também é explicado pelo menor teor de FB na composição da farinheta (Tabela 2), aliado ao seu menor DGM. No entanto, a redução do DGM no farelo grosso moído não proporcionou aumento da digestibilidade dos nutrientes e da energia, em comparação ao farelo grosso, o que reforça a ideia de que a quantidade de FB no alimento é mais relevante do que a granulometria das partículas, para a digestão em suínos.

Os valores do coeficiente de digestibilidade do cálcio (CDCa) apresentaram grande variação, embora as diferenças não tenham sido significativas (Tabela 4). Esta resposta pode acontecer em razão do baixo conteúdo de $\mathrm{Ca}$ dos subprodutos testados $(0,06 \%)$. A estimativa de coeficientes negativos, da mesma forma que os valores negativos de Ca digestível para todos os subprodutos, exceto a farinheta, indicam provável aumento na perda fecal do $\mathrm{Ca}$ da dieta referência, em complexo com o ácido fítico dos farelos de trigo. Os resultados podem estar ligados ao alto teor de fibra que os subprodutos do trigo apresentam, principalmente quando comparados à farinheta, e ao grande desbalanço de calcário resultante da inclusão de $30 \%$ do ingrediente teste na ração.

De forma similar, o coeficiente de digestibilidade do fósforo (CDP) apresentou o maior valor para a farinheta (Tabela 4), ingrediente com o menor teor de $\mathrm{P}$ e, consequentemente, de ácido fítico, nos produtos testados (Tabela 2). Este valor (em torno de 46\%) é o mesmo encontrado no National Research Council (2012), para "wheat middling", subproduto semelhante à farinheta nacional. Os CDP dos subprodutos de trigo são frequentemente mais altos do que os de outros farelos, como o de arroz (Kunrath et al., 2010), o que pode ser explicado pelo fato de, apesar do fitato reduzir a disponibilidade do $\mathrm{P}$, a fitase endógena do cereal ser mais ativa, o que melhora a retenção de $\mathrm{P}$ em suínos em crescimento (Han et al., 1997).

Quanto à fibra digestível, foram observados baixos valores de digestibilidade, os quais foram semelhantes entre os tratamentos (Tabela 4). Esses baixos valores podem estar associados ao maior teor de fibra, principalmente polissacarídeos não amiláceos, presentes nos subprodutos do trigo. Os suínos não hidrolizam adequadamente esses polissacarídeos no trato gastrointestinal (Slominski et al., 2004). O principal polissacarídeo não amiláceo do trigo são as arabinoxilanas, que podem atuar como fatores antinutricionais e comprometer a digestibilidade de outros nutrientes. Pôde-se observar que a moagem do farelo grosso não favoreceu maior fermentação e consequente maior digestibilidade da fração fibrosa.

A farinheta, com 3.460 e $3.329 \mathrm{kcal} \mathrm{kg}^{-1}$ de energia digestível e metabolizável, respectivamente, foi o subproduto com maior concentração energética (Tabela 4). Este resultado indica que a composição da farinheta e sua disponibilidade diferem das dos demais subprodutos e que, por isso, deveriam ser especificadas nas tabelas de alimentos para suínos. De acordo com as tabelas nutricionais, os valores médios de EM do farelo de trigo para suínos são baixos, o que mostra a limitação desses animais em digerir a fração de carboidratos representada pela fibra bruta, em razão da limitada capacidade fermentativa da espécie.

Os valores de EM mostraram relação negativa com o DGM dos farelos que não passaram por moagem, o que indica que frações industriais mais grossas têm menor disponibilidade energética para suínos (Tabela 4). No entanto, a moagem do farelo grosso, que diminuiu o DGM de $1.111 \mu \mathrm{m}$ para $464 \mu \mathrm{m}$, não aumentou o aproveitamento da energia. Segundo Seerley et al. (1988), a alternativa de moagem não é benéfica para todos os ingredientes, uma vez que dietas que contém grão de trigo moído nas formas mais finas tem prejudicado o ganho de peso e a conversão alimentar dos suínos.

Foram obtidas equações lineares com altos coeficientes de determinação $\left(\mathrm{R}^{2}\right)$ para as variáveis FB, FDA e FDN (Tabela 5). A FB foi a variável que proporcionou a melhor estimativa para os valores de EM. Estes resultados podem ser mostrados em equações apresentadas pelo NRC (National Research Council, 2012) e por Rostagno et al. (2011), nas quais a FB é um estimador que reduz a EM dos alimentos. As equações nas quais se empregaram, como parâmetros, os preditores FDA e FDN apresentaram resultados próximos à $\mathrm{FB}$, porém, com $\mathrm{R}^{2}$ ligeiramente inferiores.

A PB e o DGM não foram bons estimadores da EM. Quando se testou a FB, a FDA ou a FDN com a PB ou o DGM, houve um pequeno aumento no valor do $\mathrm{R}^{2}$ nas equações, mas perda na significância do modelo. 
Tabela 5. Estimativas da regressão de energia metabolizável (EM, kcal kg-1) dos subprodutos do trigo, de acordo com análise proximal.

\begin{tabular}{lccc}
\hline Estimador $^{(1)}$ & \multicolumn{1}{c}{ Equação } & $\mathrm{p}$ & $\mathrm{R}^{2}$ \\
\hline Fibra bruta (FB) & $\mathrm{EM}=4.419-188,6 \mathrm{FB}$ & 0,0058 & 0,94 \\
FDA & $\mathrm{EM}=4.656-159,9 \mathrm{FDA}$ & 0,0086 & 0,93 \\
FDN & $\mathrm{EM}=4.687-46,6 \mathrm{FDN}$ & 0,0068 & 0,94 \\
PB & $\mathrm{EM}=-6.118+501,3 \mathrm{~PB}$ & 0,0561 & 0,75 \\
DGM & $\mathrm{EM}=3.133-0,67 \mathrm{DGM}$ & 0,2964 & 0,35 \\
FB e PB & $\mathrm{EM}=3.982-182,2 \mathrm{FB}+21,5 \mathrm{~PB}$ & 0,0561 & 0,94 \\
FDA e PB & $\mathrm{EM}=969-119,8 \mathrm{FDA}+181,4 \mathrm{~PB}$ & 0,0328 & 0,97 \\
FDN e PB & $\mathrm{EM}=830-34,8 \mathrm{FDN}+190,3 \mathrm{~PB}$ & 0,0147 & 0,99 \\
FB e DGM & $\mathrm{EM}=4.453-198,1 \mathrm{FB}+0,08 \mathrm{DGM}$ & 0,0531 & 0,95 \\
FDA e DGM & $\mathrm{EM}=4.831-187,3 \mathrm{FDA}+0,26 \mathrm{DGM}$ & 0,0486 & 0,95 \\
FDN e DGM & $\mathrm{EM}=4.888-55,5 \mathrm{FDN}+0,29 \mathrm{DGM}$ & 0,0332 & 0,97 \\
\hline
\end{tabular}

${ }^{(1)}$ A percentagem do estimador na composição do subproduto foi o valor utilizado na equação. Valores obtidos com base na matéria seca. FDA, fibra em detergente ácido; FDN, fibra em detergente neutro; PB, proteína bruta; DGM, diâmetro geométrico médio.

\section{Conclusões}

1. A farinheta tem boa qualidade nutricional e energética, e é uma alternativa de uso nas dietas de suínos em crescimento.

2. A moagem reduz o diâmetro geométrico médio do farelo grosso, mas não propicia melhoria no aproveitamento dos nutrientes.

3. Equações de regressão linear, com uso da composição química dos subprodutos como parâmetros preditores, são adequadas para estimar a energia metabolizável dos subprodutos do trigo.

4. Nas equações de regressão linear, para estimar a energia metabolozável dos subprodutos do trigo, a variável fibra bruta é a que proporciona a melhor estimativa.

\section{Agradecimentos}

À Coordenação de Aperfeiçoamento de Pessoal de Nível Superior (Capes), por concessão de bolsas; ao Conselho Nacional de Desenvolvimento Científico e Tecnológico $(\mathrm{CNPq})$, pela concessão de bolsas e pelo apoio financeiro.

\section{Referências}

ASSOCIAÇÃO BRASILEIRA DA INDÚSTRIA DO TRIGO. Comparativo da estimativa aparente de moagem industrial de trigo. São Paulo: Abitrigo, 2012. 5p. (Boletim informativo, 63).
Disponível em: <http://www.abitrigo.com.br/boletins/BO_63. pdf $>$. Acesso em: 15 mar. 2013.

APOLÔNIO, L.R.; DONZELE, J.L.; OLIVEIRA, R.F.M. de; SOUZA, A.V.C. de; SILVA, F.C. de O.; BUNZEN, S. Digestibilidade ileal de aminoácidos de alguns alimentos, determinada pela técnica da cânula T simples com suínos. Revista Brasileira de Zootecnia, v.32, p.605-614, 2003. DOI: 10.1590/S1516-35982003000300012.

BLAS BEORLEGUI, C de; GONZÁLEZ MATEOS, G.; GARCÍA REBOLLAR, P. Tablas Fedna de composición y valor nutritivo de alimentos para la fabricación de piensos compuestos. 2.ed. Madrid: Fundación Española para el Desarrollo de la Nutrición Animal, 2003. 423p.

BÜNZEN, S.; ROSTAGNO, H.S.; LOPES, D.C.; HASHIMOTO, F.A.M.H.; GOMES, P.C.; APOLÔNIO, L.R. Digestibilidade do fósforo de alimentos de origem vegetal determinada com suínos em crescimento e terminação. Revista Brasileira de Zootecnia, v.37, p.1236-1242, 2008. DOI: 10.1590/S1516-35982008000700014.

CAMPBELL, G.L.; CAMPBELL, L.D.; BLAIR, R. Calculation of metabolizable energy for ingredients incorporated at low levels into a reference diet. Poultry Science, v.62, p.705-707, 1983. DOI: 10.3382/ps.0620705.

CARRE, B. Causes for variation in digestibility of starch among feedstuffs. World's Poultry Science Journal, v.60, p.76-89, 2004. DOI: 10.1079/WPS20036.

DOBRASZCZYK, B.J.; WHITWORTH, M.B.; VINCENT, J.F.V.; KHAN, A.A. Single kernel wheat hardness and fracture properties in relation to density and the modelling of fracture in wheat endosperm. Journal of Cereal Science, v.35, p.245-263, 2002. DOI: $10.1006 /$ jcrs.2001.0399.

EECKHOUT, W.; DE PAEPE, M. The quantitative effects of an industrial microbial phytase and wheat phytase on the apparent phosphorus absorbability of a mixed feed by piglets. Medical Faculty Landbouwwetenschappen Rijksuniversiteit Gent, v.56, p.1643-1648, 1991.

FANG, R.J.; LI, T.J.; YIN, F.G.; YIN, Y.L.; KONG, X.F.; WANG, K.N.; YUAN, Z.; WU, G.Y.; HE, J.H.; DENG, Z.Y.; FAN, M.Z. The additivity of true or apparent phosphorus digestible values in some feed ingredients for growing pigs. Asian-Australasian Journal of Animal Sciences, v.20, p.1092-1099, 2007.

GOERING, H.K.; VAN SOEST, P.J. Forage fiber analysis (apparatus, reagents, procedures, and some applications). Washington: Agricultural Research Service, 1970. 79p.

GOMES, J.D.F.; PUTRINO, S.M.; GROSSKLAUS, C.; UTIYAMA, C.E.; OETTING, L.L.; SOUZA, L.W. de O.; FUKUSHIMA, R.S.; FAGUNDES, A.C.A.; SOBRAL, P.J. do A.; LIMA, C.G. de. Efeitos do incremento de fibra dietética sobre a digestibilidade, desempenho e características de carcaça: I. suínos em crescimento e terminação. Semina: Ciências Agrárias, v.28, p.483-492, 2007.

HAN, Y.M.; YANG, F.; ZHOU, A.G.; MILLER, E.R.; KU, P.K.; HOGBERG, M.G.; LEI, X.G. Supplemental phytases of microbial and cereal sources improve dietary phytate phosphorus utilization by pigs from weaning through finishing. Journal of Animal Science, v.75, p.1017-1025, 1997. 
HORWITZ, W. Official methods of analysis of AOAC International. $18^{\text {th }}$ ed. Washington: AOAC International, 2005.

HUANG, S.X.; SAUER, W.C.; MARTY, B.; HARDIN, R.T. Amino acid digestibilities in different samples of wheat shorts for growing pigs. Journal of Animal Science, v.77, p. 2469-2477, 1999.

KUNRATH, M.A.; KESSLER, A. de M.; RIBEIRO, A.M.L.; VIEIRA, M.deM.; SILVA, G.L.daS.; PEIXOTO, F.D. Metodologias de avaliação do valor nutricional do farelo de arroz desengordurado para suínos. Pesquisa Agropecuária Brasileira, v.45, p.1172-1179, 2010. DOI: 10.1590/S0100-204X2010001000017.

NATIONAL RESEARCH COUNCIL. Nutrient Requirements of Swine. $11^{\text {th }}$ ed. Washington: National Academy, 2012. 400p.

NOBLET, J.; SHI, X.S.; DUBOIS, S. Metabolic utilization of dietary energy and nutrients for maintenance energy requirements in sows: basis for a net energy system. British Journal of Nutrition, v.70, p.407-419, 1993. DOI: 10.1079/ BJN19930135.

NORTEY, T.N.; PATIENCE, J.F.; SANDS, J.S; TROTTIER, N.L; ZIJLSTRA, R.T. Effects of xylanase supplementation on the apparent digestibility and digestible content of energy, amino acids, phosphorus, and calcium in wheat and wheat by-products from dry milling fed to grower pigs. Journal of Animal Science, v.86, p.3450-3464, 2008. DOI: 10.2527/jas.2007-0472.

ROSTAGNO, H.S.; ALBINO, L.F.T.; DONZELE, J.L.; GOMES, P.C.; OLIVEIRA, R.F.; LOPES, D.C.; FERREIRA, A.S.;
BARRETO, S.L.T.; EUCLIDES, R.F. Tabelas brasileiras para aves e suínos: composição dos alimentos e exigências nutricionais. 3.ed. Viçosa: UFV, 2011. 252p.

ROSTAGNO, H.S.; BUNZEN, S.; SAKOMURA, N.K.; ALBINO, L.F.T. Avanços metodológicos na avaliação de alimentos e exigências nutricionais para aves e suínos. Revista Brasileira de Zootecnia, v.36, p.295-304, 2007. DOI: 10.1590/ S1516-35982007001000027.

SAKOMURA, N.K.; ROSTAGNO, H.S. Métodos de pesquisa em nutrição de monogástricos. Jaboticabal: FUNEP, 2007. 283p.

SEERLEY, R.W.; VANDERGRIFT, W.L; HALE, O.M. Effect of particle size of wheat on performance of nursery, growing and finishing pigs. Journal of Animal Science, v.66, p.2484-2489, 1988.

SILVA, G. Caracterização e digestibilidade dos farelos fino e grosso de trigo. 2006. 29p. Dissertação (Mestrado) - Universidade Federal Rural de Pernambuco, Recife.

SLOMINSKI, B.A.; BOROS, D.; CAMPBELL, L.D.; GUENTER, W.; JONES, O. Wheat by-products in poultry nutrition. Part I. Chemical and nutritive composition of wheat screenings, bakery by-products and wheat mill run. Canadian Journal of Animal Science, v.84, p.421-428, 2004.

ZANOTTO, D.L.; BELLAVER, C. Método de determinação da granulometria de ingredientes para uso em rações de suínos e aves. Concórdia: Embrapa-CNPSA, 1996. 5p. (Embrapa-CNPSA. Comunicado técnico, 215).

Recebido em 26 de agosto de 2012 e aprovado em 29 de janeiro de 2013

Pesq. agropec. bras., Brasília, v.48, n.2, p.203-210, fev. 2013

DOI: 10.1590/S0100-204X2013000200011 